\title{
Volume-outcome relationship in pediatric neurotrauma care: analysis of two national databases
}

\author{
Oliver Y. Tang, BS, ${ }^{1}$ James S. Yoon, BS, ${ }^{2}$ Anna R. Kimata, ${ }^{1}$ and Michael T. Lawton, MD ${ }^{3}$ \\ ${ }^{1}$ The Warren Alpert Medical School of Brown University, Providence, Rhode Island; ${ }^{2}$ Yale School of Medicine, New Haven, \\ Connecticut; and ${ }^{3}$ Department of Neurological Surgery, Barrow Neurological Institute, St. Joseph's Hospital and Medical Center, \\ Phoenix, Arizona
}

\begin{abstract}
OBJECTIVE Previous research has demonstrated the association between increased hospital volume and improved outcomes for a wide range of neurosurgical conditions, including adult neurotrauma. The authors aimed to determine if such a relationship was also present in the care of pediatric neurotrauma patients.
\end{abstract}

METHODS The authors identified 106,146 pediatric admissions for traumatic intracranial hemorrhage (tICH) in the National Inpatient Sample (NIS) for the period 2002-2014 and 34,017 admissions in the National Trauma Data Bank (NTDB) for 2012-2015. Hospitals were stratified as high volume (top 20\%) or low volume (bottom 80\%) according to their pediatric $\mathrm{tICH}$ volume. Then the association between high-volume status and favorable discharge disposition, inpatient mortality, complications, and length of stay (LOS) was assessed. Multivariate regression modeling was used to control for patient demographics, severity metrics, hospital characteristics, and performance of neurosurgical procedures.

RESULTS In each database, high-volume hospitals treated over $60 \%$ of pediatric tICH admissions. In the NIS, patients at high-volume hospitals presented with worse severity metrics and more frequently underwent neurosurgical intervention over medical management (all $p<0.001$ ). After multivariate adjustment, admission to a high-volume hospital was associated with increased odds of a favorable discharge (home or short-term facility) in both databases (both $p<0.001$ ). However, there were no significant differences in inpatient mortality $(p=0.208)$. Moreover, high-volume hospital patients had lower total complications in the NIS and lower respiratory complications in both databases (all $p<0.001)$. Although patients at high-volume hospitals in the NTDB had longer hospital stays $(\beta$-coefficient $=1.17, p<0.001)$, they had shorter stays in the intensive care unit $(\beta$-coefficient $=0.96, p=0.024)$. To determine if these findings were attributable to the trauma center level rather than case volume, an analysis was conducted with only level I pediatric trauma centers (PTCs) in the NTDB. Similarly, treatment at a high-volume level I PTC was associated with increased odds of a favorable discharge (OR 1.28, $p=0.009)$, lower odds of pneumonia (OR 0.60, $p=0.007)$, and a shorter total LOS ( $\beta$-coefficient = $0.92, p=0.024)$.

CONCLUSIONS Pediatric tICH patients admitted to high-volume hospitals exhibited better outcomes, particularly in terms of discharge disposition and complications, in two independent national databases. This trend persisted when examining level I PTCs exclusively, suggesting that volume alone may have an impact on pediatric neurotrauma outcomes. These findings highlight the potential merits of centralizing neurosurgery and pursuing regionalization policies, such as interfacility transport networks and destination protocols, to optimize the care of children affected by traumatic brain injury.

https://thejns.org/doi/abs/10.3171/2019.8.FOCUS19486

KEYWORDS traumatic brain injury; pediatric trauma; health policy; volume-outcome relationship; National Inpatient Sample; National Trauma Data Bank

A MONG traumatic injuries in children, brain injuries most commonly result in death or permanent disability. ${ }^{3}$ Approximately 475,000 children under 14 years old sustain a traumatic brain injury annually, with 37,000 hospitalized across a spectrum of hospital types.,24
Given the continued prevalence of and multidisciplinary care required for pediatric neurotrauma, it is important to research system-based solutions that can benefit neurotrauma patients at the population level. For example, documentation of lower mortality rates at level

ABBREVIATIONS ACS = American College of Surgeons; ARDS = acute respiratory distress syndrome; GCS = Glasgow Coma Scale; ICU = intensive care unit; ISS = Injury Severity Score; NIS = National Inpatient Sample; NTDB = National Trauma Data Bank; LOS = length of stay; PTC = pediatric trauma center; tICH = traumatic intracranial hemorrhage; VOR = volume-outcome relationship.

SUBMITTED July 1, 2019. ACCEPTED August 22, 2019.

INCLUDE WHEN CITING DOI: 10.3171/2019.8.FOCUS19486. 
I trauma centers has guided the development of emergency transport patterns. ${ }^{10,14,35}$ Research on the volumeoutcome relationship (VOR), the relationship between hospital volume and outcomes, for neurotrauma care may also help to inform these policies. Several studies have demonstrated evidence of improved outcomes at highvolume hospitals across neurosurgical subspecialties, including tumor, vascular, and functional., ${ }^{4,12,15,34}$ Despite a more limited evidence base for pediatric neurosurgery, partly because of the lower overall volume, ${ }^{25}$ positive VORs have also been observed for pediatric procedures, including ventriculoperitoneal shunting and tumor resection..$^{40,41}$ Evidence of VORs within neurosurgery has spurred discussion on measures to centralize neurosurgical care, such as developing "centers of excellence," to improve outcomes. ${ }^{11,37}$

In the context of neurotrauma, Clement et al. demonstrated that adult traumatic intracranial hemorrhage $(\mathrm{tICH})$ patients at hospitals with a high neurotrauma volume exhibited better outcomes, including reduced mortality and higher rates of a favorable discharge. ${ }^{10}$ However, to our knowledge, no study has assessed the VOR of neurotrauma care for pediatric patients specifically. Given the different clinical considerations between children and adults in the setting of trauma, ${ }^{3,16,17}$ a separate evaluation is necessary to determine if the advantages conferred by a higher hospital volume also apply to pediatric neurotrauma care. We used two national databases in the present study to evaluate the association between hospital volume and outcomes for pediatric tICH patients. Like Clement et al., ${ }^{10}$ we analyzed pediatric tICH as a proxy for all pediatric neurotrauma. Our aim was to determine if there is a pediatric neurotrauma VOR that can inform systemic changes in neurosurgical care to optimize outcomes for children with brain injury.

\section{Methods}

\section{Data Sources: National Inpatient Sample and National Trauma Data Bank}

We analyzed pediatric tICH admissions from two independent national databases: the National Inpatient Sample (NIS) and the National Trauma Data Bank (NTDB). The NIS is the largest national, all-payer inpatient database. ${ }^{20}$ It is a $20 \%$ stratified random sample of all US community hospital discharges, representing over 7 million admissions annually. The NTDB is the largest registry of US trauma patients, composed of admissions at over 700 participating trauma centers. ${ }^{2}$ Through our dual database approach, we were able to study a nationally generalizable cohort of patients across 13 years by using the NIS and to conduct a more detailed analysis of physiological parameters and trauma center level by using the NTDB. Because of the publicly available and declassified nature of the two databases, this study was exempt from institutional review board approval.

\section{Inclusion and Exclusion Criteria and Volume Stratification}

Admissions in both databases contain diagnosis and procedure codes classified by the International Classification of Diseases, Ninth Revision. In the NIS for the
TABLE 1. Characteristics of pediatric $\mathrm{tICH}$ admissions in the NIS

\begin{tabular}{|c|c|}
\hline Variable & No. $(\%)$ \\
\hline Mean age in yrs & $9.5 \pm 7.0$ \\
\hline \multicolumn{2}{|l|}{ Sex } \\
\hline Male & $70,506(66.8 \%)$ \\
\hline Female & $34,974(33.2 \%)$ \\
\hline \multicolumn{2}{|l|}{ Race } \\
\hline White & $46,858(57.4 \%)$ \\
\hline Black & $11,625(14.2 \%)$ \\
\hline Hispanic & $16,062(19.7 \%)$ \\
\hline Asian & $1,979(2.4 \%)$ \\
\hline Native American & $868(1.1 \%)$ \\
\hline Other & $4,192(5.1 \%)$ \\
\hline \multicolumn{2}{|l|}{ Insurance status } \\
\hline Medicaid & $40,376(38.2 \%)$ \\
\hline Private insurance & $53,925(51.0 \%)$ \\
\hline Self-pay & $5,493(5.2 \%)$ \\
\hline No charge & $238(0.2 \%)$ \\
\hline Other & $5,729(5.4 \%)$ \\
\hline \multicolumn{2}{|l|}{ Income level of zip code } \\
\hline Quartile 1 (bottom) & $28,359(29.8 \%)$ \\
\hline Quartile 2 & $24,940(26.2 \%)$ \\
\hline Quartile 3 & $22,744(23.9 \%)$ \\
\hline Quartile 4 (top) & $19,231(20.2 \%)$ \\
\hline \multicolumn{2}{|l|}{ Hospital ownership } \\
\hline Government, nonfederal & $21,012(20.3 \%)$ \\
\hline Private, nonprofit & $76,673(74.1 \%)$ \\
\hline Private, for-profit & $5,759(5.6 \%)$ \\
\hline \multicolumn{2}{|l|}{ Hospital location \& teaching status } \\
\hline Rural & $2,679(2.5 \%)$ \\
\hline Urban, nonteaching & $15,324(14.5 \%)$ \\
\hline Urban, teaching & $87,336(82.9 \%)$ \\
\hline \multicolumn{2}{|l|}{ Hospital region } \\
\hline Northeast & $16,400(15.5 \%)$ \\
\hline Midwest & $22,734(21.4 \%)$ \\
\hline South & $43,166(40.7 \%)$ \\
\hline West & $23,846(22.5 \%)$ \\
\hline \multicolumn{2}{|l|}{ APR-DRG severity of illness rating } \\
\hline 1 (minor) & $37,858(36.0 \%)$ \\
\hline 2 (moderate) & $25,549(24.3 \%)$ \\
\hline 3 (major) & $21,911(20.8 \%)$ \\
\hline 4 (extreme) & $19,791(18.8 \%)$ \\
\hline \multicolumn{2}{|l|}{ APR-DRG risk of mortality rating } \\
\hline 1 (minor) & $66,119(62.9 \%)$ \\
\hline 2 (moderate) & $11,178(10.6 \%)$ \\
\hline 3 (major) & $12,519(11.9 \%)$ \\
\hline 4 (extreme) & $15,294(14.6 \%)$ \\
\hline \multicolumn{2}{|l|}{ No. of presenting $\mathrm{tICH}$ subtypes } \\
\hline 1 & $99,130(93.4 \%)$ \\
\hline$>1$ & $7,016(6.6 \%)$ \\
\hline Mean ISS & $17.0 \pm 7.5$ \\
\hline Underwent neurosurgical procedure & $16,953(16.0 \%)$ \\
\hline
\end{tabular}

APR-DRG = All Patient Refined Diagnosis Related Group.

Values are expressed as the mean \pm standard deviation, unless indicated otherwise. Percentages may not add up to $100 \%$ because of rounding, and data are missing for some variables. 

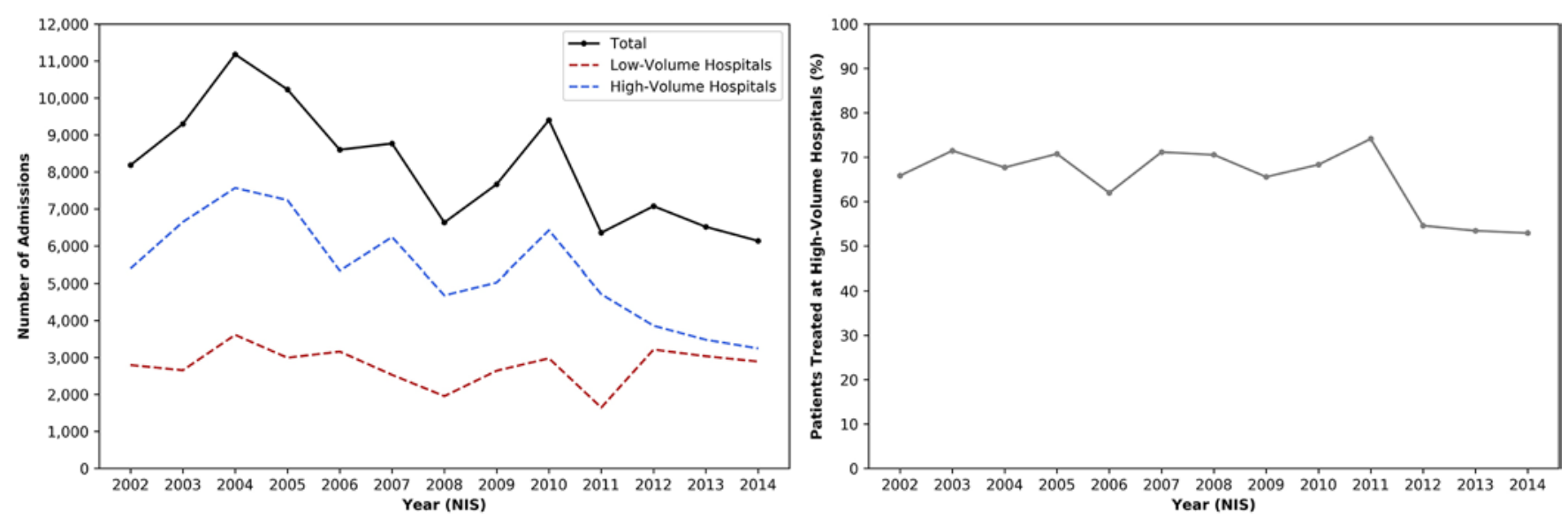

FIG. 1. Left: Number of pediatric tICH admissions to all hospitals, low-volume hospitals, and high-volume hospitals in the NIS from 2002 to 2014. Survey weights were applied to make national estimates. Right: Percentage of all pediatric tICH admissions treated at high-volume hospitals in the NIS from 2002 to 2014.

period 2002-2014 and the NTDB for 2012-2015, we identified pediatric tICH patients by selecting all admissions under 18 years of age with at least one of the following ICD-9 diagnoses for tICH: extradural hemorrhage (852.40-49, 852.50-59), subdural hemorrhage (852.20$29,852.30-39)$, subarachnoid hemorrhage (852.00-09, $852.10-19)$, or intraparenchymal hemorrhage (851.00-09, 851.10-19, 851.40-49, 851.50-59, 851.80-89, 851.90-99). We also used ICD-9 codes to record the number of presenting tICH subtypes and the neurosurgical procedure performed (01.10-01.18, 01.20-01.29, 01.39, 02.2, 02.21, 02.34), such as intracranial monitoring, decompressive craniectomy, and ventriculostomy. All NTDB patients who died on arrival were excluded. This exclusion criterion could not be applied to NIS patients given the lack of such data.

Hospitals were classified as high volume (top 20\%) or low volume (bottom 80\%) according to their annual pediatric tICH patient volume. Hospitals were stratified on an annual basis because hospitals in both databases are de-identified, making it impossible to track hospitals longitudinally. To determine if associations between hospital volume and outcomes could be explained by trauma center level, we conducted a subset analysis of American College of Surgeons (ACS)-verified level I pediatric trauma centers (PTCs) in the NTDB. Volume stratification was reperformed so that level I PTCs in the top $20 \%$ of volume among PTCs were classified as high volume.

\section{Outcomes}

For both databases, the primary outcome was favorable discharge. We assessed inpatient mortality, development of inpatient complications, and total length of stay (LOS) as secondary outcomes. Intensive care unit (ICU) LOS was also analyzed as a secondary outcome in the NTDB. Using disposition variables in both databases, discharges were categorized as favorable or unfavorable according to the criteria in Clement et al.: "routine," "transfer to short-term facility," and "discharged with home healthcare" were labeled as favorable dispositions, with all other outcomes, such as "transfer to a skilled nursing facility," labeled as unfavorable. ${ }^{10}$

For the NIS, inpatient complications were composed of six subtypes (surgical complication, deep vein thrombosis or pulmonary embolism, respiratory complication, pneumonia, urinary tract infection, and postoperative infection) derived from a systematic review on complications as a metric for trauma care performance. ${ }^{29}$ Inpatient complications were identified using ICD-9 codes extracted from Clinical Classifications Software groupings (Supplementary Table 1). The development of any inpatient complication and the six subtypes were all independently evaluated as outcomes. Unlike the NIS, the NTDB contains data on inpatient complications, avoiding the need for ICD-9 classification. For the NTDB, we analyzed the development of any complication and the three most common subtypes (pneumonia, acute respiratory distress syndrome [ARDS], and cardiac arrest) as outcomes.

\section{Statistical Analysis}

All data aggregation and analysis were performed with Stata 14 (StataCorp). For the NIS, we employed Stata's svy suite of commands to account for the database's complex survey design and apply survey weights to make national estimates.

When analyzing the association between hospital volume and patient outcomes, we constructed a multivariate model for each database to adjust for potential confounding variables. The NIS's multivariate model controlled for patient demographics (age, sex, race, insurance status, income level of zip code), admission type (weekend admission, transfer status), hospital characteristics (ownership, location/teaching status, census region), severity (severity of illness and risk of mortality scores, number of presenting tICH subtypes, Injury Severity Score [ISS], open vs closed wound), and performance of a neurosurgical procedure. The NTDB's multivariate model adjusted for patient demographics (age, sex, race, insurance status), admission type (transfer status), hospital characteristics (teaching status, census region), severity (number of comorbidities, number 
TABLE 2. Differences between low-volume and high-volume hospital admissions in the NIS

\begin{tabular}{|c|c|c|c|}
\hline Variable & Low Volume & High Volume & $\mathrm{p}$ Value \\
\hline No. of admissions & 36,106 & 70,040 & \\
\hline Mean age in yrs & $11.9 \pm 6.6$ & $8.3 \pm 6.8$ & $<0.001^{*}$ \\
\hline Sex & & & $<0.001^{*}$ \\
\hline Male & $24,625(68.9 \%)$ & $45,881(65.8 \%)$ & \\
\hline Female & $11,121(31.1 \%)$ & $23,853(34.2 \%)$ & \\
\hline Race & & & 0.187 \\
\hline White & $16,864(58.3 \%)$ & $29,994(56.9 \%)$ & \\
\hline Black & $3,909(13.5 \%)$ & $7,716(14.6 \%)$ & \\
\hline Hispanic & $5,510(19.1 \%)$ & $10,552(20.0 \%)$ & \\
\hline Asian & $895(3.1 \%)$ & $1,084(2.1 \%)$ & \\
\hline Native American & $308(1.1 \%)$ & $560(1.1 \%)$ & \\
\hline Other & $1,427(4.9 \%)$ & $2,765(5.2 \%)$ & \\
\hline Insurance status & & & $<0.001^{*}$ \\
\hline Medicaid & $11,516(32.0 \%)$ & $28,860(41.4 \%)$ & \\
\hline Private insurance & $20,261(56.3 \%)$ & $33,664(48.3 \%)$ & \\
\hline Self-pay & $2,231(6.2 \%)$ & $3,262(4.7 \%)$ & \\
\hline No charge & $32(0.1 \%)$ & $206(0.3 \%)$ & \\
\hline Other & $1,968(5.5 \%)$ & $3,761(5.4 \%)$ & \\
\hline Income level of zip code & & & 0.061 \\
\hline Quartile 1 (bottom) & $9,123(28.2 \%)$ & $19,236(30.6 \%)$ & \\
\hline Quartile 2 & $8,368(25.9 \%)$ & $16,572(26.3 \%)$ & \\
\hline Quartile 3 & $7,824(24.2 \%)$ & $14,920(23.7 \%)$ & \\
\hline Quartile 4 (top) & $7,015(21.7 \%)$ & $12,216(19.4 \%)$ & \\
\hline $\begin{array}{l}\text { APR-DRG severity of } \\
\text { illness rating }\end{array}$ & & & $<0.001^{*}$ \\
\hline 1 (minor) & $13,595(37.9 \%)$ & $24,264(35.0 \%)$ & \\
\hline 2 (moderate) & $9,032(25.2 \%)$ & $16,517(23.9 \%)$ & \\
\hline 3 (major) & $6,982(19.5 \%)$ & $14,929(21.6 \%)$ & \\
\hline 4 (extreme) & $6,259(17.5 \%)$ & $13,532(19.5 \%)$ & \\
\hline $\begin{array}{l}\text { APR-DRG risk of mortal- } \\
\text { ity rating }\end{array}$ & & & $0.007 \dagger$ \\
\hline 1 (minor) & $23,167(64.6 \%)$ & $42,952(62.0 \%)$ & \\
\hline 2 (moderate) & $3,666(10.2 \%)$ & $7,512(10.8 \%)$ & \\
\hline 3 (major) & $4,183(11.7 \%)$ & $8,336(12.0 \%)$ & \\
\hline 4 (extreme) & $4,850(13.5 \%)$ & $10,444(15.1 \%)$ & \\
\hline $\begin{array}{l}\text { No. of presenting } \mathrm{tICH} \\
\text { subtypes }\end{array}$ & & & $0.009 \dagger$ \\
\hline 1 & $33,969(94.1 \%)$ & $65,161(93.0 \%)$ & \\
\hline$>1$ & $2,137(5.9 \%)$ & $4,879(7.0 \%)$ & \\
\hline Mean ISS & $16.7 \pm 7.8$ & $17.1 \pm 7.4$ & $0.002 \uparrow$ \\
\hline $\begin{array}{l}\text { Underwent neurosurgi- } \\
\text { cal procedure }\end{array}$ & $5,040(14.0 \%)$ & $11,913(17.0 \%)$ & $<0.001^{*}$ \\
\hline
\end{tabular}

The Mann-Whitney U-test was used to assess differences in two-class characteristics, and the Kruskal-Wallis test was used to assess differences in characteristics with more than two classes. Percentages may not add up to $100 \%$ due to rounding, and data are missing for some variables.

* Statistically significant with $p<0.001$.

† Statistically significant with $p<0.01$.

of presenting tICH subtypes, open vs closed wound, admission Glasgow Coma Scale [GCS] score, hypotension on admission), and performance of a neurosurgical procedure. The two multivariate models adjusted for different factors because of disparate variables in each database.
We analyzed binary outcomes with multivariate logistic regression and reported odds ratios. To analyze LOS outcomes, we used a generalized linear regression model with a gamma link distribution and logistic link function, idealized for right-skewed continuous data, and reported $\beta$-coefficients reflecting percent changes in LOS. For example, $\beta$-coefficient $=1.05$ denotes a $+5 \%$ increase in LOS relative to the reference category. Statistical significance was maintained at $\mathrm{p}<0.05$.

\section{Results}

\section{Study Population in the NIS}

There were 106,146 admissions for pediatric tICH in the NIS from 2002 to 2014. Patients were a mean age of $9.5 \pm 7.0$ years old (mean \pm standard deviation, range 1 month-18 years). The majority of patients were male $(67 \%)$, white $(57 \%)$, and privately insured (51\%; Table 1). The majority of admissions were at private nonprofit (74.1\%) and urban teaching (83\%) centers, and a plurality was treated in the South (41\%).

High-volume hospitals admitted 66\% ( $\mathrm{n}=70,040)$ of pediatric tICH patients (Fig. 1). Low-volume and high-volume hospitals had an average annual caseload of 4 and 32, respectively. Hospitals with over 14 cases per year were classified as high volume. Most patients were admitted to high-volume institutions every year. Compared to admissions to low-volume centers, patients admitted to highvolume hospitals were more likely to be younger, to be on Medicaid, to have higher severity of illness and risk of mortality scores, to present with multiple tICH subtypes, to have higher ISSs, and to undergo neurosurgical intervention (all $\mathrm{p}<0.01$; Table 2 ).

\section{Volume-Outcome Relationship in the NIS}

Admission to a high-volume hospital was associated with higher odds of a favorable discharge (OR 1.23, p < 0.001) and lower odds of developing an inpatient complication (OR 0.78, $\mathrm{p}<0.001$ ), even after controlling for patient, hospital, and trauma severity characteristics as well as performance of neurosurgical intervention (Fig. 2). Among complication subtypes, admissions to high-volume hospitals exhibited significantly reduced odds of developing respiratory complications (OR $0.68, \mathrm{p}<0.001)$ such as pneumothorax, acute lung injury, and ARDS. Inpatient mortality or LOS did not vary with hospital volume.

\section{Study Population in the NTDB}

There were 34,497 admissions for pediatric $\mathrm{tICH}$ in the NTDB from 2012 to 2015 . We excluded 480 patients $(1.4 \%)$ who were dead on arrival, resulting in a final population of 34,017 admissions. Patients were a mean age of $10.4 \pm 6.3$ years old (range 1 month-18 years). Similar to those in the NIS, the NTDB patients were primarily male $(67 \%)$, white $(61 \%)$, and privately insured (42\%; Table 3 ). The majority of admissions occurred at university teaching centers $(59 \%)$, and a plurality was treated in the South (40\%).

High-volume hospitals treated 64\% $(n=21,749)$ of all pediatric tICH admissions (Fig. 3). Low-volume and high-volume hospitals had an average annual volume of 


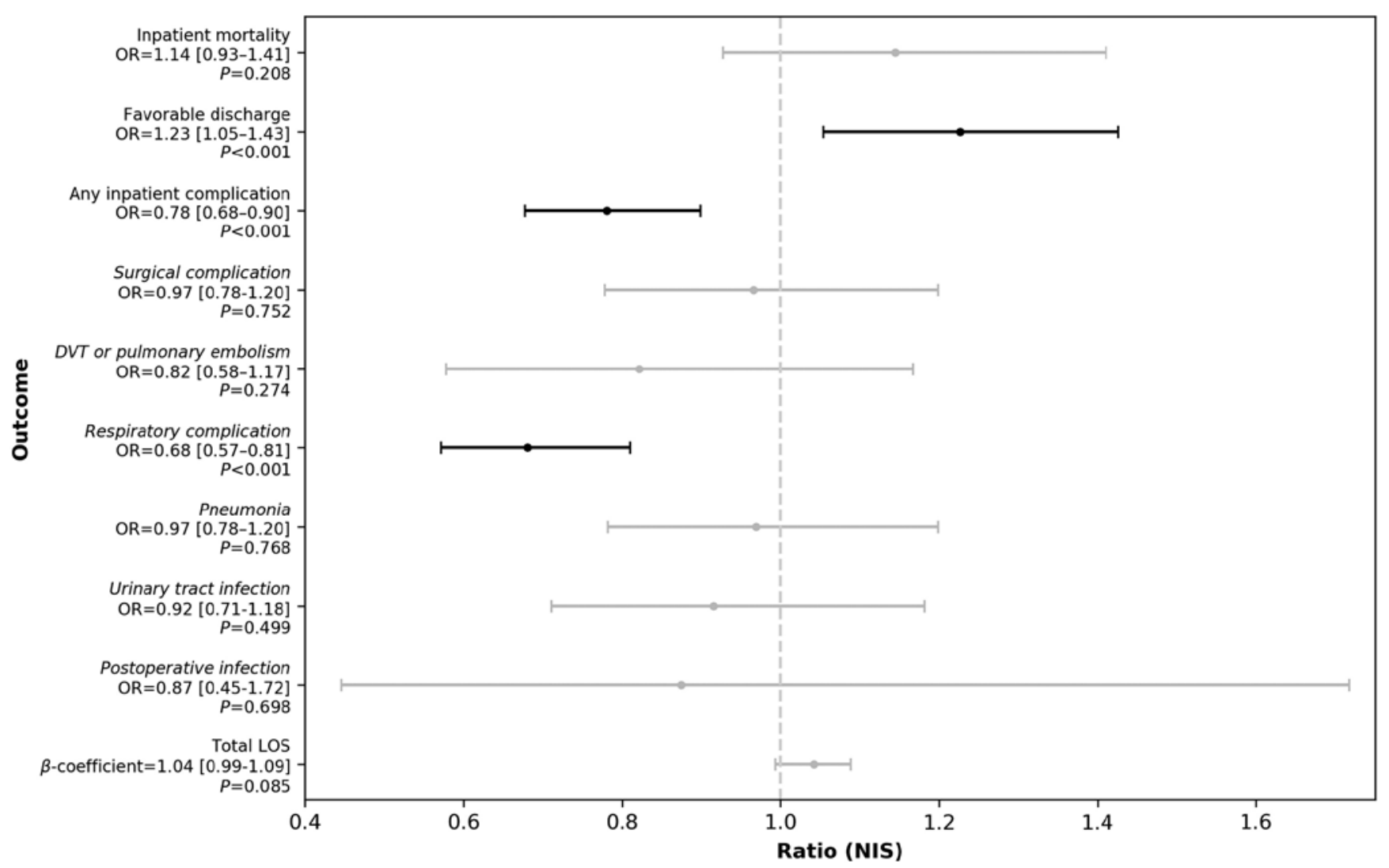

FIG. 2. Adjusted outcomes for admission to a high-volume hospital over admission to a low-volume hospital in the NIS. Multivariate regression adjusted for the same set of confounding variables for each outcome variable. For binary outcomes, odds ratios associated with admission to a high-volume hospital were reported. For total LOS, a $\beta$-coefficient corresponding to percent change relative to the reference group (admission to a low-volume hospital) was reported. The $95 \%$ confidence intervals were plotted, with significant associations colored black.

7 and 53 cases, respectively. The average threshold for a hospital to be high volume was 23 admissions per year. Most patients were admitted to high-volume centers each year. Patients at high-volume hospitals were more likely to be younger, to be on Medicaid, to be admitted with mild head injury (GCS score 13-15) and hypotension, and to undergo neurosurgical intervention (all p $<0.01$; Table 4). Moreover, high-volume hospitals had more pediatric beds and neurosurgeons (both $\mathrm{p}<0.001$ ).

\section{Volume-Outcome Relationship in the NTDB}

Following multivariate adjustment, treatment at a highvolume hospital was associated with higher odds of a favorable discharge (OR 1.27, $\mathrm{p}<0.001)$ for pediatric tICH patients but not with inpatient mortality (Fig. 4). Patients at high-volume hospitals also had reduced odds of experiencing ARDS (OR 0.71, $\mathrm{p}=0.010)$ and cardiac arrest (OR $0.47, \mathrm{p}<0.001)$. Finally, although the total LOS for highvolume hospital admissions was higher $(\beta$-coefficient $=$ $1.17, \mathrm{p}<0.001)$, the ICU LOS was reduced $(\beta$-coefficient $=0.96, \mathrm{p}=0.024)$.

\section{Subset Analysis of Level I PTCs in the NTDB}

We subsequently performed a subset analysis to exam- ine the potential impact of hospital volume specifically within level I PTCs. Twenty-two percent $(n=7638)$ of all NTDB admissions were admitted to level I PTCs from 2012 to 2015 (Supplementary Fig. 1). Forty-two percent (n $=3176$ ) of these admissions were treated at high-volume level I PTCs, indicating a lower disparity in volume between low-volume and high-volume PTCs compared to hospitals in general. Level I PTCs treated higher volumes of pediatric tICH patients compared to all hospitals in the general study population, which included institutions that were not ACS-verified, with an average of 41 and 123 admissions per year at low-volume and high-volume institutions, respectively. Level I PTCs with more than 85 annual cases were classified as high volume (top 20\%).

When solely analyzing level I PTCs, patients at highvolume institutions continued to exhibit higher odds of a favorable discharge (OR 1.28, $\mathrm{p}=0.009$; Fig. 4). Highvolume level I PTCs also had lower rates of pneumonia (OR 0.60, p = 0.007) than their low-volume counterparts. Finally, although a high volume was associated with a greater total LOS when looking at all hospitals, a highvolume status for level I PTCs predicted a lower total LOS for pediatric tICH admissions $(\beta$-coefficient $=0.92, \mathrm{p}=$ $0.024)$. 
TABLE 3. Characteristics of pediatric tICH admissions in the NTDB

\begin{tabular}{|c|c|}
\hline Variable & No. $(\%)$ \\
\hline Mean age in yrs & $10.4 \pm 6.3$ \\
\hline \multicolumn{2}{|l|}{ Sex } \\
\hline Male & $22,762(66.9 \%)$ \\
\hline Female & $11,247(33.1 \%)$ \\
\hline \multicolumn{2}{|l|}{ Race } \\
\hline White & $20,248(61.3 \%)$ \\
\hline Black & $4,748(14.4 \%)$ \\
\hline Hispanic & $5,475(16.6 \%)$ \\
\hline Asian & $737(2.2 \%)$ \\
\hline Native American & $364(1.1 \%)$ \\
\hline Other & $1,454(4.4 \%)$ \\
\hline \multicolumn{2}{|l|}{ Insurance status } \\
\hline Medicaid & $11,776(36.6 \%)$ \\
\hline Private insurance & $13,594(42.3 \%)$ \\
\hline Self-pay & $2,451(7.6 \%)$ \\
\hline Other & $4,336(13.5 \%)$ \\
\hline \multicolumn{2}{|l|}{ Hospital teaching status } \\
\hline Community & $10,165(29.9 \%)$ \\
\hline Nonteaching & $3,663(10.8 \%)$ \\
\hline University & $20,189(59.3 \%)$ \\
\hline \multicolumn{2}{|l|}{ Hospital region } \\
\hline Northeast & $5,367(15.9 \%)$ \\
\hline Midwest & $7,517(22.2 \%)$ \\
\hline South & $13,621(40.3 \%)$ \\
\hline West & $7,280(21.5 \%)$ \\
\hline Mean no. of comorbidities & $0.13 \pm 0.41$ \\
\hline \multicolumn{2}{|l|}{ No. of presenting $\mathrm{tICH}$ subtypes } \\
\hline 1 & $25,532(75.1 \%)$ \\
\hline$>1$ & $8,485(24.9 \%)$ \\
\hline \multicolumn{2}{|l|}{ GCS score on admission } \\
\hline Mild (13-15) & $21,332(65.8 \%)$ \\
\hline Moderate (9-12) & $2,091(6.4 \%)$ \\
\hline Severe $(\leq 8)$ & $9,008(27.8 \%)$ \\
\hline Hypotension on admission (<90 mm Hg) & $2,234(6.6 \%)$ \\
\hline Underwent neurosurgical procedure & $5,426(16.0 \%)$ \\
\hline
\end{tabular}

Values are expressed as the mean \pm standard deviation, unless indicated otherwise. Percentages may not add up to $100 \%$ because of rounding, and data are missing for some variables.

\section{Discussion}

We present evidence from two national databases that admission to high-volume hospitals is associated with certain improved outcomes in pediatric tICH, particularly greater odds of a favorable discharge and lower inpatient complication rates. Similar VORs have been demonstrated for neurosurgery $y^{4,11,37,40,41}$ and adult trauma care. , $^{6,32,38} \mathrm{In}$ the present study, we focused exclusively on how pediatric tICH outcomes are associated with hospital volume, rather than provider volume, because the NIS and NTDB have limited data on provider volume. Moreover, earlier research has indicated that a higher hospital caseload confers benefits beyond those impacting individual physicians. ${ }^{12,28}$ Increased hospital volume not only increases the experience of individual surgeons, but also bolsters multidisciplinary teams, processes for an entire episode of care, and the adoption of technological improvements. ${ }^{12,38}$ As a result, hospital volume is especially influential for a multidisciplinary disease process like neurotrauma, which requires high coordination for treatment. ${ }^{10,28}$ However, one of the biggest challenges to expanding the regionalization of pediatric trauma care is the limited evidence base compared to that for adult trauma, ${ }^{25,32}$ which is corroborated by the stagnated levels of treatment at high-volume hospitals since 2002. Consequently, in the present study, we aimed to characterize the VOR for pediatric neurotrauma patients in order to inform population-level quality improvement.

We found that admissions at high-volume hospitals in the NIS and NTDB had significantly higher odds of a favorable discharge. Our findings are consistent with those of several neurosurgical studies demonstrating an improved discharge status at higher-caseload hospitals. ${ }^{5,10,11,40}$ The results were especially notable for the NIS analysis because patients at high-volume hospitals had poorer measurements on every severity metric, suggesting that highvolume institutions can achieve better outcomes despite receiving more critically injured patients with greater case complexity. There are several explanations for these results. A higher volume can improve a hospital's infrastructure and integration of multidisciplinary care processes, such as dedicated pediatric trauma protocols. This can catalyze care improvements that facilitate favorable discharge, such as our finding of lower complication rates at high-volume hospitals. Specifically, patients at high-volume hospitals in both databases exhibited decreased odds of respiratory complications, which may be modulated by expertise in interdisciplinary teams of pulmonology and neurointensive care specialists. ${ }^{13}$ Furthermore, high-volume hospitals may possess more resources for adopting new treatment modalities and implementing quality improvement measures. Finally, these institutions may have better implementation of support programs (e.g., rehabilitation and social work) that improve the ultimate disposition of children afflicted with brain injury. Nevertheless, in either database, hospital volume was not associated with mortality. Given earlier findings that hospital volume is especially correlated with reduced mortality for patients with severe trauma, ${ }^{1,14,38}$ the lack of a mortality benefit may be explained by our analysis of patients with heterogeneous levels of neurotrauma severity.

The relationship between hospital volume and LOS was more complicated. While no significant association between these two variables was found in the NIS, highvolume hospital patients in the NTDB had a greater total LOS, a finding previously demonstrated for subarachnoid hemorrhage and pediatric cardiac surgery.,36 A greater LOS at high-volume hospitals may result from the higher trauma severity of admissions at these institutions. It may also be attributable to differences in care paradigms at high-volume hospitals, as in our documentation of increased neurosurgical intervention, which can prolong admissions but ultimately produce better outcomes at discharge. However, a high-volume status was contrarily associated with a lower LOS when specifically examin- 

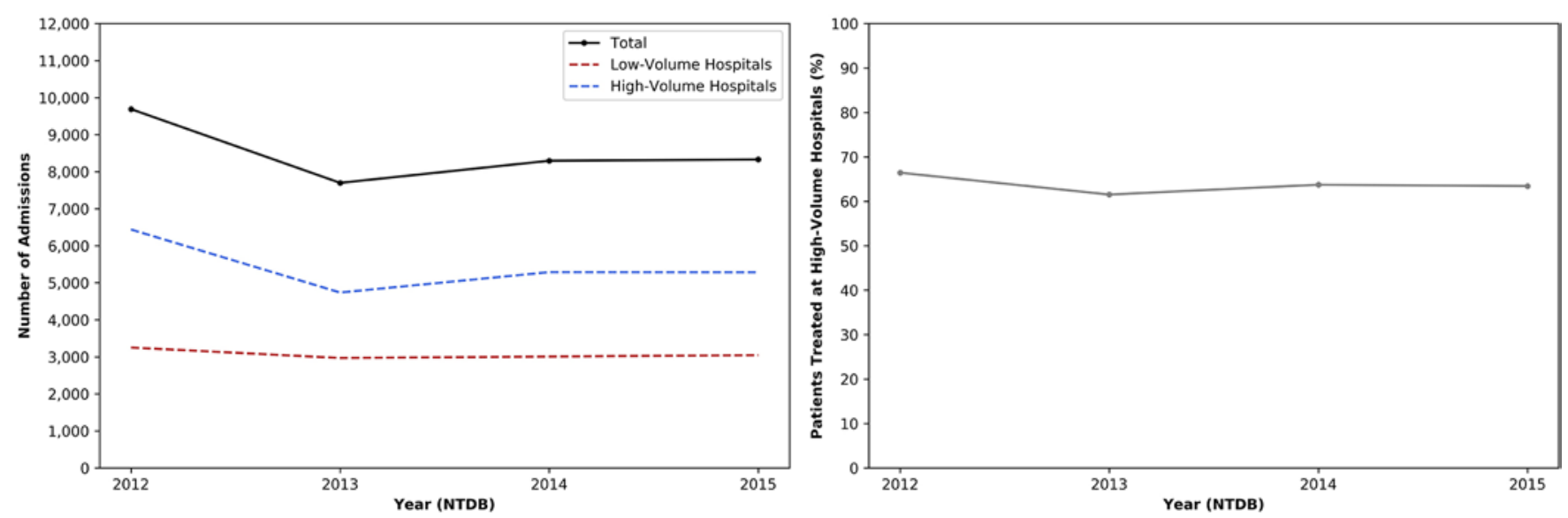

FIG. 3. Admissions for pediatric tICH in the NTDB. Left: Number of admissions to all hospitals, low-volume hospitals, and high-volume hospitals in the NTDB from 2012 to 2015. Right: Percentage of all admissions treated at high-volume hospitals in the NTDB from 2012 to 2015 .

ing level I PTCs, suggesting that these more intensive processes have learning curves and can become more efficient with the increased expertise conferred by a higher volume. Moreover, we also demonstrated that although the total LOS is greater, NTDB patients at high-volume hospitals simultaneously had shorter ICU LOSs. Greater neurosurgical coverage, experience with a high neurotrauma caseload, and the need for bed turnover at high-volume hospitals may shorten ICU stays. Furthermore, enhanced care processes at these institutions may help to prevent adverse events that extend ICU time. For example, highvolume hospital admissions were $25 \%$ less likely to experience respiratory complications in both databases. Given the well-established importance of shorter ICU stays and earlier mobilization in reducing complications, readmission, and mortality, ${ }^{21,23,27}$ this represents another potential benefit of high-volume hospitals.

Because trauma volume is a criterion for verification of level I PTCs, these centers are often overrepresented in high-volume hospitals for trauma. ${ }^{7}$ Consequently, we conducted a subset analysis of ACS-verified level I PTCs to determine if improved pediatric neurotrauma outcomes at higher-volume centers were attributable to their level I status instead of their volume. Although level I PTCs had higher pediatric neurotrauma volumes compared to hospitals in the general study population, such as hospitals without ACS verification, we still observed better outcomes for pediatric tICH patients at high-volume level I PTCs than those for patients at their low-volume counterparts, corroborating earlier findings for adult trauma care.? Consequently, other criteria for level I status, such as 24-hour in-house surgical coverage, do not exclusively explain improved pediatric tICH outcomes, and thus volume likely plays a role. Our study provides evidence that a pediatric neurotrauma VOR still exists for level I PTCs, suggesting that increasing volume may facilitate improvement of care processes at even the most experienced institutions.

Amid the continued prevalence of pediatric neurotrauma, population-wide interventions play an important role in improving outcomes. Extensive research has dem- onstrated that the organization of regional or statewide trauma systems has reduced trauma mortality by $15 \%$ $25 \% .22,26,31$ Regionalizing the treatment of neurotrauma and other neurosurgical conditions on the basis of VORs may be another promising intervention. For example, the Leapfrog Group is a private initiative that encourages insurers to centralize eight high-risk procedures with validated VORs at high-volume institutions (https://www. leapfroggroup.org/ratings-reports/surgical-volume). ${ }^{8}$ Like studies demonstrating improvements in surgical outcomes enabled by regionalization efforts, ${ }^{8,9}$ interfacility transport and referral networks that encourage the care of pediatric neurotrauma at high-volume institutions may similarly leverage this VOR to improve outcomes. Encouraging treatment at high-volume hospitals may also bolster population-wide performance improvement and injury prevention measures at these institutions. Regionalization is especially important in the context of trauma care because the acute presentation of trauma eliminates a patient's ability to make informed choices about where to seek care..$^{25}$ Consequently, consolidating neurotrauma care may help to ensure patient admission to an institution where they receive optimal treatment.

However, there are important caveats to these measures. First, as the time to treatment remains the most important determinant of neurotrauma outcomes, transferring a patient to a high-volume institution may delay treatment or decrease their medical stability. However, care at large centers can be encouraged without significantly compromising prehospital transport times by creating destination protocols that encourage the initial admission of neurotrauma patients to high-volume hospitals. ${ }^{10}$ Moreover, Nathens et al. have asserted that the time-sensitive nature of trauma actually increases the value of the institutional experience provided by higher hospital volume. ${ }^{32}$ Another concern is that centralizing neurotrauma care may overburden high-volume hospitals and compromise their quality of care. However, because an increased volume is associated with better outcomes even within level I PTCs, the hospitals with the greatest caseloads, our findings sug- 
TABLE 4. Differences between low-volume and high-volume hospital admissions in the NTDB

\begin{tabular}{|c|c|c|c|}
\hline Variable & Low Volume & High Volume & $\mathrm{p}$ Value \\
\hline No. of admissions & 12,268 & 21,749 & \\
\hline Mean age in yrs & $12.5 \pm 5.9$ & $9.2 \pm 6.2$ & $<0.001^{*}$ \\
\hline Sex & & & $<0.001^{*}$ \\
\hline Male & $8,497(69.3 \%)$ & $14,265(65.6 \%)$ & \\
\hline Female & $3,769(30.7 \%)$ & $7,478(34.4 \%)$ & \\
\hline Race & & & $<0.001^{*}$ \\
\hline White & $7,543(63.9 \%)$ & $12,705(59.9 \%)$ & \\
\hline Black & $1,520(12.9 \%)$ & $3,228(15.2 \%)$ & \\
\hline Hispanic & 1,897 (16.1\%) & $3,578(16.9 \%)$ & \\
\hline Asian & $240(2.0 \%)$ & $497(2.3 \%)$ & \\
\hline Native American & $174(1.5 \%)$ & $190(0.9 \%)$ & \\
\hline Other & $437(3.7 \%)$ & $1,017(4.8 \%)$ & \\
\hline Insurance status & & & $<0.001^{*}$ \\
\hline Medicaid & $3,406(29.4 \%)$ & $8,370(40.7 \%)$ & \\
\hline Private insurance & $5,296(45.6 \%)$ & $8,298(40.4 \%)$ & \\
\hline Self-pay & $1,086(9.4 \%)$ & $1,365(6.6 \%)$ & \\
\hline Other & $1,815(15.6 \%)$ & $2,521(12.3 \%)$ & \\
\hline Mean no. of comorbidities & $0.14 \pm 0.43$ & $0.13 \pm 0.40$ & 0.129 \\
\hline No. of presenting $\mathrm{tICH}$ & & & 0.123 \\
\hline subtypes & $9,267(75.5 \%)$ & $16,265(74.8 \%)$ & \\
\hline 1 & $3,001(24.5 \%)$ & $5,484(25.2 \%)$ & \\
\hline$>1$ & & & \\
\hline GCS score on admission & & & $0.006 \dagger$ \\
\hline Mild (13-15) & $7,515(65.0 \%)$ & $13,817(66.2 \%)$ & \\
\hline Moderate (9-12) & $809(7.0 \%)$ & $1,282(6.1 \%)$ & \\
\hline Severe $(\leq 8)$ & $3,234(28.0 \%)$ & $5,774(27.7 \%)$ & \\
\hline $\begin{array}{l}\text { Hypotension on admis- } \\
\text { sion }\end{array}$ & $662(5.4 \%)$ & $1,572(7.2 \%)$ & $<0.001^{*}$ \\
\hline $\begin{array}{l}\text { Underwent neurosurgical } \\
\text { procedure }\end{array}$ & $1,625(13.2 \%)$ & $3,801(17.5 \%)$ & $<0.001^{*}$ \\
\hline
\end{tabular}

The Mann-Whitney U-test was used to assess differences in two-class characteristics, and the Kruskal-Wallis test was used to assess differences in characteristics with more than two classes. Percentages may not add up to $100 \%$ because of rounding, and data are missing for some variables.

* Statistically significant with $p<0.001$.

† Statistically significant with $p<0.01$.

gest that high-volume institutions possess the ability to manage high volumes of patients. ' Furthermore, Bell et al. determined that a higher trauma volume is not associated with failure to rescue, which they used as a proxy for excessively strained resources. ${ }^{6}$ Finally, consolidating pediatric neurotrauma treatment away from low-volume institutions may exacerbate the financial strain and closure of these centers, which commonly operate in medically underserved areas. ${ }^{30,39}$ Over 300 trauma centers closed in the period 1990-2005..$^{39}$ Although the bottom quintile of hospitals treated less than $5 \%$ of admissions in both databases, these smaller centers may be the only source of trauma care in their region. However, regionalization initiatives present the opportunity to strengthen coordination of care within geographic regions, such as interfacility partnerships to demonstrate high-quality care paradigms to low-volume hospitals. ${ }^{711,25}$ Legislation may also seek to ameliorate areas of financial burden for these centers, such as uncompensated care. Through our exploration of the VOR for pediatric neurotrauma, we aim to encourage dialogue within the neurosurgical community on the merits and challenges of centralizing surgical care of these patients to improve outcomes.

The present study faces potential limitations. First, both databases only contain data on the index admission, preventing analysis of postdischarge outcomes such as long-term functional status. Second, coding inaccuracies in national administrative databases have been well documented, ${ }^{19,33}$ which may have affected the assessment of outcomes such as complications. Third, although we adopted our quintile-based volume stratification system from seven earlier neurosurgical studies ${ }^{12}$ alternative classification methods exist. However, a sensitivity analysis classifying the top $25 \%$ of hospitals as high volume corroborated an improved favorable discharge, our primary outcome, at high-volume hospitals in the NIS (OR 1.19, p = 0.027 ) and NTDB (OR 1.20, p < 0.001). Fourth, the NTDB may not be generalizable nationally because data are submitted voluntarily by hospitals. ${ }^{18}$ To address this, we supplemented our analysis with the NIS, an all-payer database of community hospitals representing $97 \%$ of the population, and found similar results. ${ }^{20}$ Fifth, the NIS has limited data on neurosurgery-specific variables and physiological parameters associated with neurotrauma outcomes. We aimed to rectify this limitation by using the NTDB's inclusion of physiological variables such as GCS score and hypotension, but residual confounding may exist. Finally, we acknowledge that other quality metrics for trauma centers beyond volume warrant consideration. However, our use of two databases, which complementarily addressed limitations present in each other, jointly determined that higher hospital volume was associated with better outcomes for pediatric tICH, even when exclusively considering level I PTCs. Thus, despite these limitations, we believe our findings indicate that policies guided by hospital volume can drive system-wide improvement initiatives for the care of children with neurotrauma.

\section{Conclusions}

The continued prevalence of and the complex care process for pediatric neurotrauma necessitate further research on population-level solutions. In this study, we demonstrate evidence from two national databases that highvolume hospitals may deliver superior care for pediatric tICH, with patients at these institutions having significantly higher odds of a favorable discharge and lower complication rates. In the NIS, these benefits were present even though high-volume centers treat more severely injured admissions. Moreover, a subset analysis in the NTDB supported findings that a higher hospital volume has a positive effect even among level I PTCs, including greater odds of a favorable discharge, lower pneumonia rates, and shorter LOS. In light of these findings, a promising system-level initiative to improve outcomes for children with tICH may be encouraging the care of these patients at high-volume institutions through reforms to consolidate pediatric neurotrauma care at these institutions. Regionalization efforts 
Tang et al.
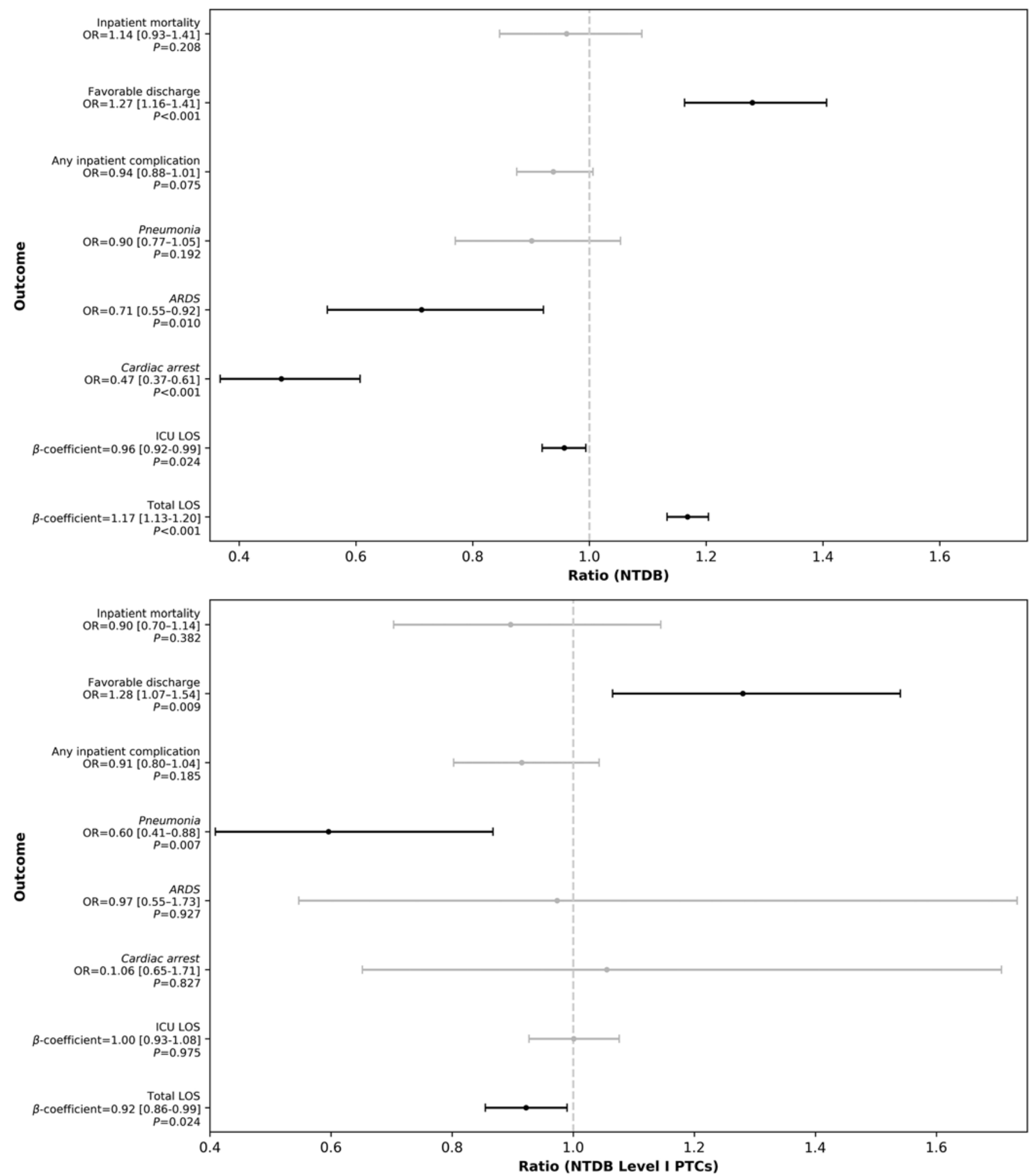

FIG. 4. Adjusted outcomes for admission to a high-volume hospital over admission to a low-volume hospital in the NTDB. Multivariate regression adjusted for the same set of confounding variables for each outcome variable. For binary outcomes, odds ratios associated with admission to a high-volume hospital were reported. For LOS outcomes, a $\beta$-coefficient corresponding to percent change relative to the reference group (admission to a low-volume hospital) was reported. The $95 \%$ confidence intervals were plotted, with significant associations colored black. Upper: All admissions in the NTDB. Lower: Level I PTC admissions in the NTDB. Stratification was reperformed for level I PTCs. 
to accomplish this, such as emergency transport networks, interfacility referral guidelines, and destination protocols, deserve future discussion.

\section{References}

1. Alali AS, Gomez D, McCredie V, Mainprize TG, Nathens AB: Understanding hospital volume-outcome relationship in severe traumatic brain injury. Neurosurgery 80:534-542, 2017

2. American College of Surgeons: About NTDB. FACS.org (https://www.facs.org/quality-programs/trauma/tqp/centerprograms/ntdb/about) [Accessed September 4, 2019]

3. Araki T, Yokota H, Morita A: Pediatric traumatic brain injury: characteristic features, diagnosis, and management. Neurol Med Chir (Tokyo) 57:82-93, 2017

4. Bardach NS, Olson SJ, Elkins JS, Smith WS, Lawton MT, Johnston SC: Regionalization of treatment for subarachnoid hemorrhage: a cost-utility analysis. Circulation 109:22072212, 2004

5. Bardach NS, Zhao S, Gress DR, Lawton MT, Johnston SC: Association between subarachnoid hemorrhage outcomes and number of cases treated at California hospitals. Stroke 33:1851-1856, 2002

6. Bell TM, Boustany KC, Jenkins PC, Zarzaur BL: The relationship between trauma center volume and in-hospital outcomes. J Surg Res 196:350-357, 2015

7. Bennett KM, Vaslef S, Pappas TN, Scarborough JE: The volume-outcomes relationship for United States level I trauma centers. J Surg Res 167:19-23, 2011

8. Birkmeyer JD, Finlayson EV, Birkmeyer CM: Volume standards for high-risk surgical procedures: potential benefits of the Leapfrog initiative. Surgery 130:415-422, 2001

9. Birkmeyer JD, Lucas FL, Wennberg DE: Potential benefits of regionalizing major surgery in Medicare patients. Eff Clin Pract 2:277-283, 1999

10. Clement RC, Carr BG, Kallan MJ, Wolff C, Reilly PM, Malhotra NR: Volume-outcome relationship in neurotrauma care. J Neurosurg 118:687-693, 2013

11. Davies JM, Lawton MT: Improved outcomes for patients with cerebrovascular malformations at high-volume centers: the impact of surgeon and hospital volume in the United States, 2000-2009. J Neurosurg 127:69-80, 2017

12. Davies JM, Ozpinar A, Lawton MT: Volume-outcome relationships in neurosurgery. Neurosurg Clin N Am 26:207218, viii, 2015

13. Della Torre V, Badenes R, Corradi F, Racca F, Lavinio A, Matta B, et al: Acute respiratory distress syndrome in traumatic brain injury: how do we manage it? J Thorac Dis 9:5368-5381, 2017

14. Demetriades D, Martin M, Salim A, Rhee P, Brown C, Chan L: The effect of trauma center designation and trauma volume on outcome in specific severe injuries. Ann Surg 242:512-519, 2005

15. Eskandar EN, Flaherty A, Cosgrove GR, Shinobu LA, Barker FG II: Surgery for Parkinson disease in the United States, 1996 to 2000: practice patterns, short-term outcomes, and hospital charges in a nationwide sample. J Neurosurg 99:863-871, 2003

16. Figaji AA: Anatomical and physiological differences between children and adults relevant to traumatic brain injury and the implications for clinical assessment and care. Front Neurol 8: 685, 2017

17. Giza CC, Mink RB, Madikians A: Pediatric traumatic brain injury: not just little adults. Curr Opin Crit Care 13:143152,2007

18. Goble S, Neal M, Clark DE, Nathens AB, Annest JL, Faul M, et al: Creating a nationally representative sample of patients from trauma centers. J Trauma 67:637-644, 2009
19. Gologorsky Y, Knightly JJ, Chi JH, Groff MW: The Nationwide Inpatient Sample database does not accurately reflect surgical indications for fusion. J Neurosurg Spine 21:984993, 2014

20. Healthcare Cost and Utilization Project: Overview of the National (Nationwide) Inpatient Sample (NIS). Rockville, MD: Healthcare Cost and Utilization Project, 2018 (https:// www.hcup-us.ahrq.gov/nisoverview.jsp) [Accessed September 4, 2019]

21. Hunter A, Johnson L, Coustasse A: Reduction of intensive care unit length of stay: the case of early mobilization. Health Care Manag (Frederick) 33:128-135, 2014

22. Jurkovich GJ, Mock C: Systematic review of trauma system effectiveness based on registry comparisons. J Trauma 47 (3 Suppl):S46-S55, 1999

23. Kirschen MP, Francoeur C, Murphy M, Traynor D, Zhang B, Mensinger JL, et al: Epidemiology of brain death in pediatric intensive care units in the United States. JAMA Pediatr 173:469-476, 2019

24. Langlois JA, Rutland-Brown W, Thomas KE: The incidence of traumatic brain injury among children in the United States: differences by race. J Head Trauma Rehabil 20:229-238, 2005

25. Lorch SA, Myers S, Carr B: The regionalization of pediatric health care. Pediatrics 126:1182-1190, 2010

26. MacKenzie EJ, Rivara FP, Jurkovich GJ, Nathens AB, Frey KP, Egleston BL, et al: A national evaluation of the effect of trauma-center care on mortality. N Engl J Med 354:366378, 2006

27. Mahesh B, Choong CK, Goldsmith K, Gerrard C, Nashef SA, Vuylsteke A: Prolonged stay in intensive care unit is a powerful predictor of adverse outcomes after cardiac operations. Ann Thorac Surg 94:109-116, 2012

28. McAteer JP, LaRiviere CA, Drugas GT, Abdullah F, Oldham $\mathrm{KT}$, Goldin AB: Influence of surgeon experience, hospital volume, and specialty designation on outcomes in pediatric surgery: a systematic review. JAMA Pediatr 167:468-475, 2013

29. Moore L, Stelfox HT, Turgeon AF: Complication rates as a trauma care performance indicator: a systematic review. Crit Care 16:R195, 2012

30. Mosley D, DeBehnke D: Rural Hospital Sustainability: New analysis shows worsening situation for rural hospitals, residents. Navigant Consulting. February 22, 2019 (https:// www.navigant.com/insights/healthcare/2019/rural-hospitalsustainability) [Accessed September 4, 2019]

31. Mullins RJ, Mann NC: Population-based research assessing the effectiveness of trauma systems. J Trauma 47 (3 Suppl):S59-S66, 1999

32. Nathens AB, Jurkovich GJ, Maier RV, Grossman DC, MacKenzie EJ, Moore M, et al: Relationship between trauma center volume and outcomes. JAMA 285:1164-1171, 2001

33. Nouraei SA, Hudovsky A, Frampton AE, Mufti U, White NB, Wathen CG, et al: A study of clinical coding accuracy in surgery: implications for the use of administrative big data for outcomes management. Ann Surg 261:1096-1107, 2015

34. Nuño M, Mukherjee D, Carico C, Elramsisy A, Veeravagu A, Black KL, et al: The effect of centralization of caseload for primary brain tumor surgeries: trends from 2001-2007. Acta Neurochir (Wien) 154:1343-1350, 2012

35. Oyetunji TA, Haider AH, Downing SR, Bolorunduro OB, Efron DT, Haut ER, et al: Treatment outcomes of injured children at adult level 1 trauma centers: are there benefits from added specialized care? Am J Surg 201:445-449, 2011

36. Sakai-Bizmark R, Mena LA, Kumamaru H, Kawachi I, Marr $\mathrm{EH}$, Webber EJ, et al: Impact of pediatric cardiac surgery regionalization on health care utilization and mortality. Health Serv Res 54:890-901, 2019

37. Schwartz TH: A role for centers of excellence in transsphenoidal surgery. World Neurosurg 80:270-271, 2013 
38. Sewalt CA, Wiegers EJA, Venema E, Lecky FE, Schuit SCE, Den Hartog D, et al: The volume-outcome relationship in severely injured patients: a systematic review and meta-analysis. J Trauma Acute Care Surg 85:810-819, 2018

39. Shen YC, Hsia RY, Kuzma K: Understanding the risk factors of trauma center closures: do financial pressure and community characteristics matter? Med Care 47:968-978, 2009

40. Smith ER, Butler WE, Barker FG II: Craniotomy for resection of pediatric brain tumors in the United States, 1988 to 2000: effects of provider caseloads and progressive centralization and specialization of care. Neurosurgery 54:553565,2004

41. Smith ER, Butler WE, Barker FG II: In-hospital mortality rates after ventriculoperitoneal shunt procedures in the United States, 1998 to 2000: relation to hospital and surgeon volume of care. J Neurosurg 100 (2 Suppl Pediatrics):90-97, 2004

\section{Disclosures}

The authors report no conflict of interest concerning the materials or methods used in this study or the findings specified in this paper.

\section{Author Contributions}

Conception and design: Lawton, Tang, Yoon. Acquisition of data: Tang. Analysis and interpretation of data: Lawton, Tang, Kimata. Drafting the article: Tang, Yoon, Kimata. Critically revising the article: Tang, Yoon, Kimata. Reviewed submitted version of manuscript: all authors. Approved the final version of the manuscript on behalf of all authors: Lawton. Statistical analysis: Tang, Yoon, Kimata. Study supervision: Lawton.

\section{Supplemental Information \\ Online-Only Content}

Supplemental material is available online.

Supplementary Table and Figure. https://thejns.org/doi/suppl/ 10.3171/2019.8.FOCUS19486.

\section{Previous Presentations}

Preliminary data for this study were presented as an oral presentation at the 47th Annual Meeting of the AANS/CNS Section on Pediatric Neurological Surgery held in Nashville, TN, on December 6-9, 2018.

\section{Correspondence}

Michael T. Lawton: Barrow Neurological Institute, St. Joseph's Hospital and Medical Center, Phoenix, AZ. michael.lawton@ barrowbrainandspine.com. 